\title{
Testosterone Treatment Improves Insulin Resistance in Japanese Male Metabolic Syndrome
}

Ueshiba $\mathrm{H}^{*}$

Department of Internal Medicine, Toho University School of Medicine, Tokyo, Japan

\begin{abstract}
The metabolic syndrome involves a cluster of clinical features including visceral obesity, insulin resistance, hypertension, glucose intolerance, and dyslipidemia. Recent studies have shown that low testosterone levels are significantly associated with metabolic syndrome and type 2 diabetes. We examined the change in insulin resistance after testosterone treatment in five Japanese men with metabolic syndrome and low free testosterone levels (age : $50.2 \pm 8.7 \mathrm{yrs}$, BMI : $30.5 \pm 5.0$, waist : $97 \pm 7 \mathrm{~cm}$; Mean \pm SD). Testosterone supplements were administered by intramuscular injection ( $250 \mathrm{mg}$ every 2 weeks) for 3 to 6 months. Fasting plasma glucose (FPG), fasting serum insulin (F-IRI), HbA1c, total cholesterol(TCHO), triglyceride(TG), HDL-C, LDL-C, free testosterone, LH, FSH, BMI and waist circumference were measured. We used homeostasis model assessment (HOMA-R) as an index of insulin resistance and investigated the change in insulin resistance after testosterone treatment. Average results before treatment were as follows: BMI $30.5 \pm 5.0$, waist $97 \pm 7 \mathrm{~cm}$, FPG $112 \pm 6 \mathrm{mg} / \mathrm{dl}$, F-IRI $25.1 \pm 8.5 \mu \mathrm{lU} / \mathrm{ml}, \mathrm{HOMA}-\mathrm{R} 7.0 \pm 2.7, \mathrm{HbA} 1 \mathrm{c}(\mathrm{NGSP})$ $5.8 \pm 0.3 \%$, TCHO $227 \pm 31 \mathrm{mg} / \mathrm{dl}$, TG $185 \pm 64 \mathrm{mg} / \mathrm{dl}$, HDL-C $43 \pm 9 \mathrm{mg} / \mathrm{dl}$, LDL-C $149 \pm 37 \mathrm{mg} / \mathrm{dl}$, free testosterone $5.9 \pm 1.0 \mathrm{pg} / \mathrm{ml}$, LH $1.7 \pm 0.6 \mathrm{IU} / \mathrm{ml}$, FSH $3.7 \pm 0.7 \mathrm{IU} / \mathrm{ml}$. After treatment, F-IRI, HOMA-R, TCHO and LDL-C were significantly decreased to $12.9 \pm 3.6 \mu \mathrm{lU} / \mathrm{ml}, 3.3 \pm 1.1199 \pm 29 \mathrm{mg} / \mathrm{dl}$ and $120 \pm 31 \mathrm{mg} / \mathrm{dl}$, respectively. Free testosterone was significantly increased to $8.5 \pm 0.6 \mathrm{pg} / \mathrm{ml}$. Other parameters were not changed significantly. In conclusion, these results suggest that testosterone treatment improves insulin resistance in Japanese men with metabolic syndrome and low free testosterone levels.
\end{abstract}

Keywords: Testosterone; Insulin resistance; Metabolic syndrome

\section{Introduction}

Levels of testosterone, an androgenic hormone, have long been known to decrease with aging, and a low testosterone level has been said to be related to diabetes mellitus, obesity, cardiovascular diseases, osteoporosis and decreased libido. Low testosterone levels can reportedly predict insulin resistance and the onset of type 2 diabetes mellitus [1-3]. It has also been reported that testosterone and insulin levels correlate negatively in healthy men [4-6] and also that testosterone replacement therapy improves insulin sensitivity [7]. Moreover, a recent report showed a relationship of low testosterone levels with metabolic syndrome.

Insulin resistance is considered to be a strong underlying contributor to metabolic syndrome, which has recently been receiving considerable research attention. The present study assessed changes in insulin resistance after administration of a testosterone preparation in male subjects with metabolic syndrome who had a low free testosterone level.

\section{Methods}

\section{Subjects}

Five men (mean age [mean \pm SD], $50.2 \pm 8.7$ years; body mass index (BMI), $30.5 \pm 5.0$; waist circumference, $97 \pm 7 \mathrm{~cm}$ ) with metabolic syndrome who had a low free testosterone level were studied. Free testosterone levels below $8.5 \mathrm{pg} / \mathrm{mL}$ were defined as low, according to the Japanese guidelines for treatment of late-onset hypogonadism. Metabolic syndrome was diagnosed based on the diagnostic criteria used in Japan, i.e., having a waist circumference of $85 \mathrm{~cm}$ or more for men, and meeting at least 2 of the following 3 criteria: (1) systolic blood pressure of $130 \mathrm{mmHg}$ or higher and/or diastolic blood pressure of 85 $\mathrm{mmHg}$ or higher; (2) fasting blood glucose of $110 \mathrm{mg} / \mathrm{dL}$ or higher; and (3) blood triglyceride of $150 \mathrm{mg} / \mathrm{dL}$ or higher and/or blood high density lipoprotein (HDL)-cholesterol below $40 \mathrm{mg} / \mathrm{dL}$. Of the 5 subjects, 3 were taking antihypertensive agents and 2 were taking antihyperlipidemic agents. Adequate informed consent to participate in this study was obtained from all 5 subjects.

\section{Methods}

A testosterone enanthate (Enarmon Depot Intramuscular Injection $250 \mathrm{mg}$, every 2 weeks) was administered to the subjects. Before and 3 to 6 months after administration of the testosterone enanthate, BMI, waist circumference, fasting plasma glucose (FPG), fasting plasma immunoreactive insulin (F-IRI), HbA1c, homeostasis model assessment ratio (HOMA-R), total cholesterol (TCHO), triglyceride (TG), HDL-cholesterol (HDL-C), low density lipoprotein-cholesterol (LDL-C), free testosterone (Free-Testo), luteinizing hormone(LH), and follicle-stimulating hormone(FSH) were measured and the changes in these parameters were compared. HOMA-R was calculated from FPG and F-IRI values: HOMA-R=FPG $(\mathrm{mg} / \mathrm{dL}) \times \mathrm{F}-\mathrm{IRI}(\mu \mathrm{U} / \mathrm{mL}] / 405$. The results are displayed as mean $\pm \mathrm{SD}$. Student's $t$-test was employed, and a difference was considered to be statistically significant when the hazard ratio was less than $5 \%$.

\section{Results}

The changes in the parameters after versus before administration

*Corresponding author: Ueshiba H, Department of Internal Medicine, Toho University School of Medicine, Tokyo, Japan, E-mail: ueshiba@med.toho-u.ac.jp

Received June 01, 2013; Accepted July 21, 2013; Published July 26, 2013

Citation: Ueshiba H (2013) Testosterone Treatment Improves Insulin Resistance in Japanese Male Metabolic Syndrome. J Steroids Horm Sci 4: 116. doi:10.4172/21577536.1000116

Copyright: @ 2013 Ueshiba H. This is an open-access article distributed under the terms of the Creative Commons Attribution License, which permits unrestricted use, distribution, and reproduction in any medium, provided the original author and source are credited. 
Citation: Ueshiba H (2013) Testosterone Treatment Improves Insulin Resistance in Japanese Male Metabolic Syndrome. J Steroids Horm Sci 4: 116. doi:10.4172/2157-7536.1000116

of the testosterone preparation are presented in Table 1. F-IRI decreased significantly from $25.1 \pm 8.5 \mu \mathrm{IU} / \mathrm{mL}$ before administration to $12.9 \pm 3.6 \mu \mathrm{IU} / \mathrm{mL}$ after administration. HOMA-R also decreased significantly from $7.0 \pm 2.7$ to $3.3 \pm 1.1$. As to the lipid profile, TCHO decreased from $227 \pm 31 \mathrm{mg} / \mathrm{dL}$ before administration to $199 \pm 29$ $\mathrm{mg} / \mathrm{dL}$ after administration, and LDL-C from $149 \pm 37 \mathrm{mg} / \mathrm{dL}$ to 120 $\pm 31 \mathrm{mg} / \mathrm{dL}$, with both decreases being significant. Administration of the testosterone enanthate significantly increased blood free testosterone from $5.9 \pm 1.0 \mathrm{pg} / \mathrm{mL}$ to $8.5 \pm 0.6 \mathrm{pg} / \mathrm{mL}$, and the changes in this parameter were considered to be attributable to the effects of testosterone. Changes in F-IRI, HOMA-R, TCHO, LDL-C, and Free-Testo in individual subjects are presented in Figures 1-5. The parameters related to insulin resistance (F-IRI and HOMA-R) were reduced in all 5 subjects, while those related to the lipid profile (TCHO and LDL-C) decreased markedly in some subjects but only slightly in the others. Thus, inter-patient differences in these parameters were suspected. No significant changes after versus before administration of the testosterone enanthate were observed in the other parameters (BMI, waist circumference, FPG, HbA1c, TG, HDL-C, LH, and FSH).

\section{Discussion}

In the present study, administration of a testosterone enanthate to male subjects with metabolic syndrome, who at baseline had a low free testosterone level, resulted in improvement of HOMA-R, an index of

\begin{tabular}{|c|c|c|c|}
\hline & Before & After & \\
\hline $\mathrm{BMI}\left(\mathrm{kg} / \mathrm{m}^{2}\right)$ & $30.5 \pm 5.0$ & $30.8 \pm 4.6$ & \\
\hline waist $(\mathrm{cm})$ & $97 \pm 7$ & $95 \pm 6$ & \\
\hline $\mathrm{FPG}(\mathrm{mg} / \mathrm{dl})$ & $112 \pm 6$ & $109 \pm 9$ & \\
\hline $\mathrm{F}-\mathrm{IRI}(\mu \mathrm{lU} / \mathrm{ml})$ & $25.1 \pm 8.5$ & $12.9 \pm 3.6$ & $\mathrm{P}<0.01$ \\
\hline $\mathrm{HbA} 1 \mathrm{c}(\%)(\mathrm{NGSP})$ & $5.8 \pm 0.3$ & $5.7 \pm 0.4$ & \\
\hline $\mathrm{HOMA}-\mathrm{R}$ & $7.0 \pm 2.7$ & $3.3 \pm 1.1$ & $\mathrm{P}<0.01$ \\
\hline $\mathrm{TCHO}(\mathrm{mg} / \mathrm{dl})$ & $227 \pm 31$ & $199 \pm 29$ & $\mathrm{P}<0.05$ \\
\hline $\mathrm{TG}(\mathrm{mg} / \mathrm{dl})$ & $185 \pm 64$ & $188 \pm 47$ & \\
\hline $\mathrm{HDL}-\mathrm{C}(\mathrm{mg} / \mathrm{dl})$ & $43 \pm 9$ & $47 \pm 12$ & \\
\hline $\mathrm{LDL}-\mathrm{C}(\mathrm{mg} / \mathrm{dl})$ & $149 \pm 37$ & $120 \pm 31$ & $\mathrm{P}<0.05$ \\
\hline $\begin{array}{c}\mathrm{Free}- \\
\text { Testosterone}(\mathrm{pg} /\end{array}$ & $5.9 \pm 1.0$ & $8.5 \pm 0.6$ & $\mathrm{P}<0.05$ \\
\hline $\mathrm{ml})$ & $1.7 \pm 0.6$ & $1.8 \pm 0.6$ & \\
\hline $\mathrm{LH}(\mathrm{IU} / \mathrm{ml})$ & $3.7 \pm 0.7$ & $3.7 \pm 0.6$ & \\
\hline $\mathrm{FSH}(\mathrm{IU} / \mathrm{ml})$ & & & \\
\hline
\end{tabular}

Table 1: Changes of clinical parameters before and after testosterone treatment.

\section{F-IRI}

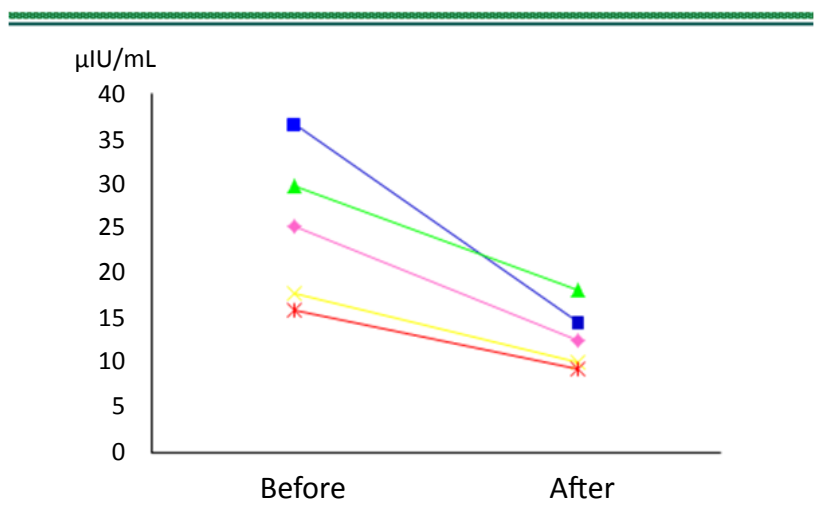

Figure 1: Changes in F-IRI before and after testosterone treatment.

\section{HOMA-R}

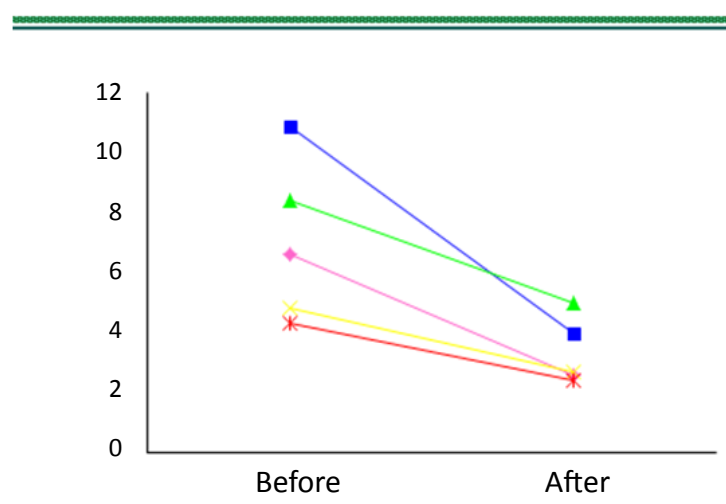

Figure 2: Changes in HOMA-R before and after testosterone treatment.

\section{$\mathrm{TCHO}$}

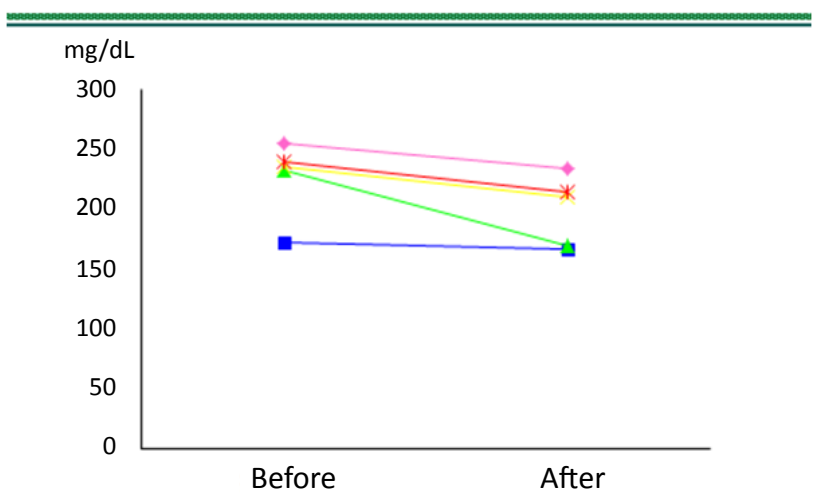

Figure 3: Changes in $\mathrm{TCHO}$ before and after testosterone treatment.

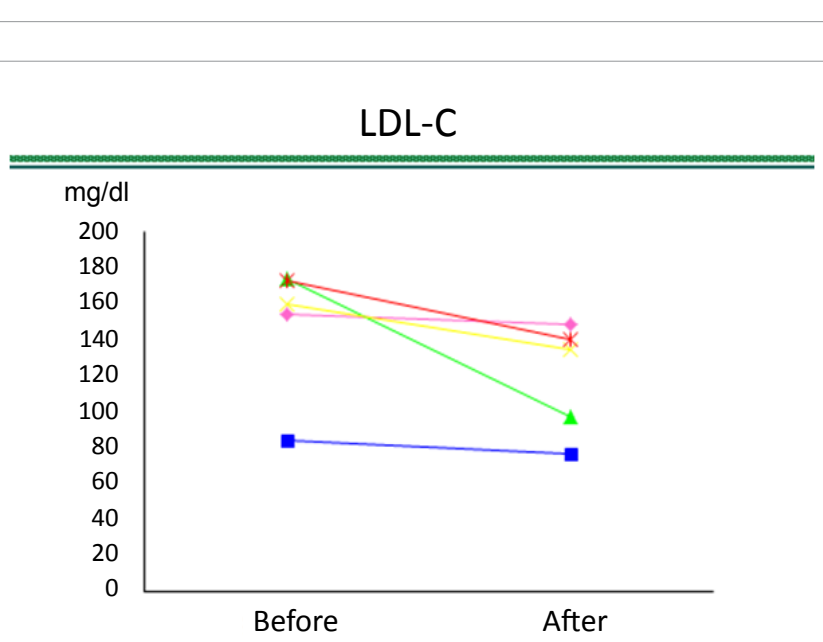

Figure 4: Changes in LDL-C before and after testosterone treatment.

insulin resistance, as well as improvements in TCHO and LDL-C levels in some subjects. These results are considered to be important as they raise the possibility that testosterone improves lifestyle-related disease conditions.

Japanese patients with diabetes mellitus reportedly have lower 


\section{Free-Testosterone}

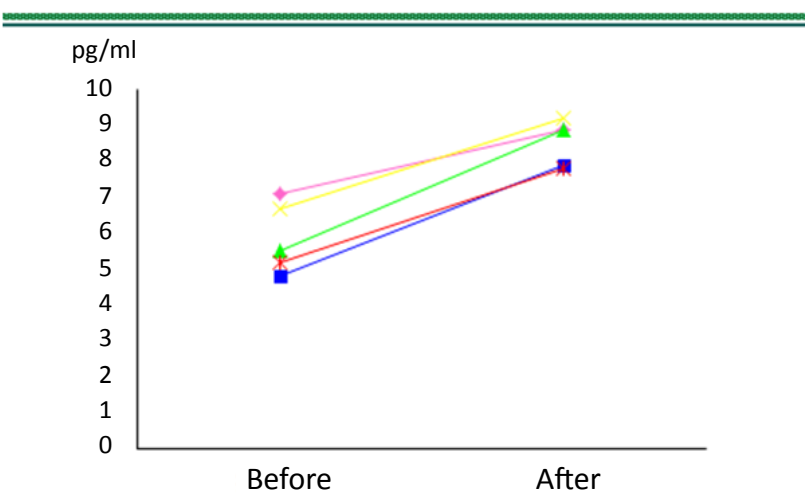

Figure 5: Changes in Free-Testosterone before and after testosterone treatment.

testosterone levels than healthy people of the same age [8]. Diabetes mellitus is associated not only with obesity and increased insulin resistance but also with depression, sleep disorders, cognitive impairment, and sexual dysfunction. Diabetic patients are also a high-risk group for cardiovascular diseases. These symptoms are considered to be attributable, at least partly, to decreased testosterone levels. Diabetic animals were reported to have reduced numbers of Leydig cells in the testes and decreased testosterone secretion [9]. This is hypothesized to be a consequence of microcirculatory dysfunction of the testes due to hyperglycemia. As to humans, it has also been reported that blood testosterone and blood glucose levels were inversely correlated in non-diabetic men [10]. The Endocrine Society of the United States recommends measurement of blood testosterone because decreased testosterone occurs at a high rate in patients with type 2 diabetes mellitus. There is a report describing an investigation of factors determining serum testosterone in male patients with type 2 diabetes mellitus [11]. Testosterone was reported to show a strong inverse correlation with age and a significant positive correlation with total cholesterol. Since sex hormones are produced from cholesterol, caution is required regarding an excessive decrease in cholesterol as this may lead to a decrease in testosterone. Hyperinsulinemia related to obesity is also said to have an effect on Leydig cells, thereby reducing the secretion of testosterone.

Decreases in androgenic hormone levels lead to insulin resistance and promote the onset of lifestyle-related diseases such as diabetes mellitus, dyslipidemia, and hypertension. Hyperglycemia and insulin resistance in turn decrease the secretion of testosterone. To stop this vicious cycle, lifestyle improvements to reduce obesity and hyperinsulinemia/hyperglycemia are important as an initial step. Hormone replacement therapy implemented as necessary is also considered to be useful.
Reduction of visceral fat is speculated to be a possible mechanism by which a testosterone treatment improves insulin resistance in men with metabolic syndrome. However, no significant changes in BMI or waist circumference were observed in this study. The testosterone treatment was administered for 6 months at the most in this study, and administration over a longer period may be required to achieve significant decreases in BMI and waist circumference. This issue is anticipated to be clarified in future studies. In hypogonadal men with type 2 diabetes, there is a report that testosterone replacement therapy improves insulin resistance, glycemic control, visceral adiposity and hypercholesterolemia. In this report, although patients were treated with intramuscular testosterone $200 \mathrm{mg}$ every 2 weeks for 3 months, testosterone treatment resulted in a reduction in visceral adiposity as assessed by waist circumference and waist/hip ratio. For longterm treatment of testosterone, transcutaneous administration of an ointment formulation may prove to yield more favorable compliance than intramuscular injection.

\section{Conclusion}

It is suggest that testosterone treatment improves insulin resistance in Japanese men with metabolic syndrome and low free testosterone levels.

\section{References}

1. Oh JY, Connor EB, Wedick NM, Wingard DL (2002) Endogenous Sex Hormones and the Development of Type 2 Diabetes in Older Men and Women: the Rancho Bernardo Study. Diabetes care 25: 55-60.

2. Stellato RK, Feldman HA, Hamdy O, Horton ES, McKinlay JB (2000) Testosterone, sex hormone-binding globulin, and the development of type 2 diabetes in middle-aged men: prospective results from the Massachusetts male aging study. Diabetes care 23: 490-494.

3. Haffner SM, Shaten J, Stem MP, Smith GD, Kuller L (1996) Low Levels of Sex Hormone-binding Globulin and Testosterone Predict the Development of NonInsulin-dependent Diabetes Mellitus in Men. Am J Epidemiol 143: 889-897.

4. Simon D, Preziosi P, Barrett-Connor E, Roger M, Saint-Paul M, et al. (1992) Interrelation between plasma testosterone and plasma insulin in healthy adult men: the Telecom Study. Diabetologia 35: 173-177.

5. Barrett-Connor E, Khaw KT (1988) Endogenous sex hormones and cardiovascular disease in men. A prospective population-based study. Circulation 78: 539-545.

6. Kapoor D, Goodwin E, Channer KS, Jones TH (2006) Testosterone replacement therapy improves insulin resistance, glycaemic control, viscera adiposity and hypercholesterolaemia in hypogonadal men with type 2 diabetes. Eur J Endocrinol 154: 899-906.

7. Kupelian V, Hayes FJ, Link CL, Rosen R, Mckinlay JB (2008) Inverse Association of Testosterone and the Metabolic Syndrome in Men Is Consistent across Race and Ethnic Groups. J Clin Endocrinol Metab 93: 3403-3410.

8. Fukui M, Soh J, Tanaka, Kitagawa Y, Hasegawa G, et al. (2007) Low Serum Testosterone Concentration in Middle-aged Men with Type 2 Diabetes. Endocr J 54: 871-877.

9. Jackson FL, Hutson JC (1984) Altered Responses to Androgen in Diabetic Male Rats. Diabetes 33: 819-824.

10. Haffner SM, Karhappa P, Mykkanen L, Laakso M (1994) Insulin Resistance Body Fat Distribution, and Sex Hormones in Men. Diabetes 43: 212-219.

11. Fukui M, Kitawaga y, Nakamura N, Kadono M, Mogami S, et al. (2003) Association Between Serum Testosterone Concentration and Carotid Atherosclerosis in Men With Type 2 Diabetes. Diabetes care 26: 1869-1873.

This article was originally published in a special issue, Steroid Hormones and Obesity and Type 2 Diabetes handled by Editor. Dr. Chamindie Punyadeera, University of Queensland, Australia 